\title{
Instruction of mathematical concepts through analogical reasoning skills
}

\author{
Somayeh Amir-Mofidi ${ }^{1}$, Parvaneh Amiripour ${ }^{1 *}$ and Mohammad H.Bijan-zadeh ${ }^{2}$ \\ ${ }^{1}$ Department of Mathematics, Science and Research Branch, Islamic Azad University, Tehran, Iran \\ ${ }^{2}$ Department of Mathematics, The center for graduate studies, Payamenoor University, Tehran, Iran \\ *Parvaneh.Amiripour@mailfa.org
}

\begin{abstract}
For learning the mathematical concepts need to have special skills. Reasoning is skill that uses to teach and learn. These reasoning must have harmony to real life. Analogical reasoning is reasoning skill that made to better learning in mathematical context. In this research, analogical reasoning skills have been instructed on 20 students of first grade in girly high school and the results of the Leven and independent samples tests have shown that instruction through analogical reasoning improves the mathematical learning. Therefore it seems that instruction of mathematical concepts through analogical reasoning modify the misconceptions and difficult of mathematical problems for students.
\end{abstract}

Keywords: Mathematics, Analogical reasoning, Inductive reasoning, Deductive reasoning, Instruction.

\section{Introduction}

Students find mathematical concepts and principles to abstract to comprehend. One of the methods that teachers apply to assist students with building conceptual knowledge is to use analogies. Richland et al. (2004) point out that mathematics and distant (non-math) analogies drawn from non-mathematics contents are generated by teachers or educators routinely. When we use non-math analogies in mathematics classes or textbook, we observe in students a lowered level of math anxiety, deeper understanding of concepts being taught, deeper understanding of what we are doing when doing math, better memorization of the skills taught, and ease in building connections between different strands of mathematics (Sarina \& Namukasa, 2010). Mathematics textbooks proved to be the scary source of analogies or non-math examples. Many textbooks, despite their inclusion of real life contexts and pictures, shy away from employing non-math contexts, especially analogies, as an explanation tool when handling more abstract or advanced topics. We have found only few analogies that are prominently presented in textbooks. For example, the Function is compared to a machine that has input and output slots (Sarina \& Namukasa, 2010).

Mathematics is an excellent source of anecdotal evidence of specific math concepts that students find hard to comprehend and the strategies they can use to facilitate their comprehension. Whatever is important in mathematical context, is the students' reasoning ability along analogy. The reasoning ability or mathematical thinking is defined as "a dynamics process which, by enabling us to increase the complexity of ideas we can handle, expands our understanding" (Mason et al., 1991). While Schoenfeld (1992) has defined it as the development of a mathematical point of view- valuing the process of mathematization and abstraction and having the predilection to apply them; and the development of competence with tools of the trade, and using those tools in the service of the goal of understanding structure (Zaman et al., 2011). Reasoning ability can help students to understand and evaluate scientific and technological society. Because, reasoning is highly effective for students' ability to analyze new situations, which are faced in all aspects; make logical assumptions, explain their thoughts, reach conclusions and defense their conclusions.

Reasoning is defined as the act of using reason to derive a conclusion from certain premises. Reasoning styles or their components may be arising from students learning styles. Identifying relationship with the learning and reasoning styles of students can provide educators with valuable information in designing their curriculum. According to Hawk and Shah (2007), adult students learn in different ways, faculty in higher education would have a responsibility to expand their repertoire of learning activities to embrace as wide a field of adult student learning styles as possible in order to achieve more effective learning (Arslan et al., 2009). There is no general agreement between the researchers in the field about the nature of analogy. Michalski (1986 \& 1989) considers analogy as a two steps process with the first step being induction and the second one-deduction.

On the contrary, Holyoak and his collaborators (Holland et al., 1986) consider the induction step as a consequence of a successful analogy. A widespread (and broadly accepted) definition of analogy is that it is a mapping between elements of a source domain and a target domain. Gentner (1989) states that "analogy is a mapping of knowledge from one domain (the base) into another (the target), which conveys that a system of relations that hold among the base objects also holds among the target objects. Thus, an analogy is a way of focusing on relational commonalities independently of the objects in which those relations are embedded. People prefer to map connected systems of relations governed by higher-order relations with inferential import, rather than isolated predicates". Holland et al. (1986) consider analogy as a second-order quasi-homomorphism where the model of one real domain is considered as a model of another domain. The aim of this research is to state the
Sci.Technol.Edu.

CIndian Society for Education and Environment (iSee)
"Instruction of mathematical concepts"

http://www.indjst.org
S.A-Mofidi et al. Indian J.Sci.Technol. 
Fig. 1. Categories of reasoning

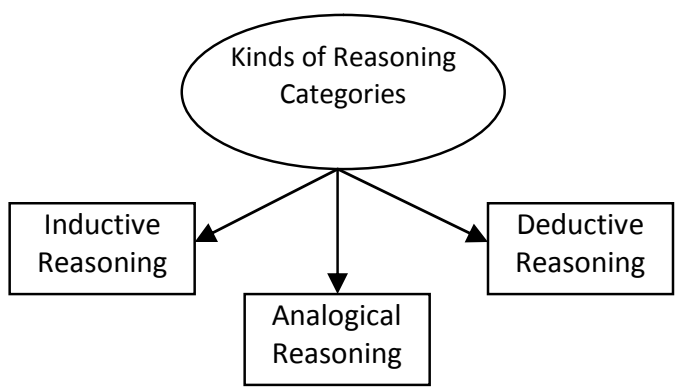

kinds of reasoning and explain the analogical reasoning along examples in mathematics instruction exactly.

The kinds of reasoning categories

Most students can remember at least one occasion when they failed to solve a problem at their first attempt at it, but succeeded, and without great difficulties at that, if they had a second chance later. Moreover, students also happen to be unable to solve for a second time a problem they have successfully solved before. It is also quite common for students to find various solutions of the same problem in various occasions. As a rule, this variability and flexibility of human problem solving behavior is ignored by models of thinking, reasoning and problem solving generally. Whatever clears, is that there are general three reasoning in problem solving moment (see Fig.1). In this section, researchers have tried to introduce three reasoning in particular analogical reasoning.

\section{Inductive reasoning}

Through the inductive process of reasoning, understanding is derived from consideration of observable characteristics. One is able to generalize from facts acquired through observation. Inductive reasoning is one of the important characteristics of human intelligence: inductive reasoning as one of the seven primary mental abilities that are accounted for intelligent behaviors. Merriam-Webster on-line dictionary defined induction as an "inference of a generalized conclusion from particular instances". Pellegrino and Glaser (1982) noted that the induction reasoning ability can be extracted in most aptitude and intelligent tests and is the best predictor for academic performance. Harverty et al. (2000) cited several other researches that viewed inductive reasoning as a significant factor for problem solving, concept learning, mathematic learning, and development of expertise, and Heller (2001) showed that inductive reasoning is necessary ability for extracting the knowledge of problem solving in physics. The term induction is derived from the Latin rendering of Aristotle's epagoge that is the process for moving to a generalization from its specific instances.

Bransford (2000) pointed out that generalizations aimed at increasing transferability (ability to apply to a different context) can result in (mathematical) models, or global hypothesis in terms of Harverty et al. (2000). These can be later applied to a variety of contexts in an efficient manner. Zhu and Simon (1987) pointed out that the learners have to induce how and when to apply the problem solving method in worked-out examples. In reality, the learners also need to induce where to apply with a contextual awareness. The induction here requires the learners to (1) recognize the similarities and differences of the parameters in the current and the experienced contexts, (2) recognize and match pattern of current context to the experienced context(s), and/or (3) recognize/create the hypothesis/method that can be applied to solve the problem, (2) recognize and match pattern of current context to the experienced context(s), and/or (3) recognize/create the hypothesis/method that can be applied to solve the problem (Moreno et al., 2007).

First we have indicated how students explain inductive reasoning from non-mathematical example. For instance, teachers stated a short story for students in classroom; a person enters to unknown village. He observed a person from that village who has blue eyes. When he enters to teashop, he saw that all people have blue eyes at there. What do you think? All students stated that we concluded that all people from that village have blue eyes. Therefore all students stated self-inductive reasoning. This reasoning is general conclusion base on limited set of observations. Now we will prove the following problem through inductive reasoning:

Problem 1. Prove for any $\mathrm{n} \geq 0$ that

$\frac{1}{2}+\frac{1}{2^{2}}+\cdots+\frac{1}{2^{n}}=1-\frac{1}{2^{n}}$

Proof: If $\mathrm{n}=1$ then;

$\frac{1}{2^{1}}=\frac{1}{2}=1-\frac{1}{2^{1}}$

We see that equality (1) is to correct in this case.

If $n=2$ then

$\frac{1}{2^{1}}+\frac{1}{2^{2}}=\frac{3}{4}=1-\frac{1}{2^{1}}$

This shows that the equality (1) is to correct again. We can attain to this equality through the addition of the equality (2) and $\frac{1}{2^{2}}$ :

\section{$\left(1-\frac{1}{2^{1}}\right)+\frac{1}{2^{2}}=\frac{3}{2^{2}}=1-\frac{1}{2^{2}}$}

The continuance of this study is not practical for all numbers then what do we work? We study $n=3$ using attained results for first two sentences:

$\left(\frac{1}{2}+\frac{1}{2^{2}}\right)+\frac{1}{2^{3}}=\left(1-\frac{1}{2^{2}}\right)+\frac{1}{2^{3}}=\frac{7}{2^{3}}=1-\frac{1}{2^{3}}$

We concluded the accuracy of relation for $n=3$. Now if we supposed the accuracy of relation for $n=k$ generally, that is

$\frac{1}{2}+\frac{1}{2^{2}}+\frac{1}{2^{3}}+\cdots+\frac{1}{2^{\mathrm{k}}}=1-\frac{1}{2^{\mathrm{k}}}$

And if we concluded the accuracy of above relation for $\mathrm{n}=\mathrm{k}+1$ through this assumption, then we can acclaim that the equality (1) is corrective in any cases. 
$\left(\frac{1}{2}+\frac{1}{2^{2}}+\frac{1}{2^{3}}+\cdots+\frac{1}{2^{k}}\right)+\frac{1}{2^{k+1}}=1-\frac{1}{2^{k+1}}$

In first party of the equality (7), we replace its equivalent; $\left(1-\frac{1}{2^{\mathrm{k}}}\right)$ from equality (1) stead the value of parenthesis:

$\left(1-\frac{1}{2^{k}}\right)+\frac{1}{2^{k+1}}$

$=1-\frac{2}{2^{k+1}}+\frac{1}{2^{k+1}}$

$=1-\frac{1}{2^{\mathrm{k}+1}}$

Through accuracy of relation in $n=k$, its accuracy is proved in $n=k+1$ also. This example indicated that could prove difficult mathematical problems and started via small instances until we generalized in general case.

Deductive reasoning

Deductive reasoning is a broad term covering the encoding and combination of statements using logical connectives, transitive inference or syllogistic reasoning and propositional reasoning. Deductive reasoning involves the process of logically deriving facts, outcomes or consequences, from ideas or theories based on the formal truth relationships between premises without regard for the empirical or practical truth-value of the premises. Effective reasoning requires the ability to develop arguments and assess their validity to generate and test hypotheses, to judge the plausibility of assertions, to identify possible courses of action, and to think through the consequences of choosing a particular course (Watters \& English, 1995).

Deductive reasoning plays an important role in scientific explanation and prediction. Given general causal laws and statements, describing initial condition deductive reasoning can be viewed as a specific domain of knowledge. Deductive reasoning can help students to recognize cognitive conflict and to resolve it (Park \& Han, 2002). To define the functional unity of any deductive construction, Duval and Egret (1989) uses the term "Arc Transitive of Substitution" (A.T.S.) which corresponds either to a minimal length demonstration, or to a step in a demonstration constituted by a continuation of recurring substitution.

According to Duval and Egret (1989) two aspects of deductive reasoning are, the number of conditions to be taken into account to apply correctly a rule of substitution and the ternary structure-not binary-of the A.T.S.; the basic unity of any deductive construction contains three statements (given statement, rule of substitution, new statement), each having a different status (Arslan et al., 2009). When we use the deductive reasoning, we will sure that the result is corrective always. Deductive reasoning is conclusion method via using facts which we have accepted its accuracy. We used mathematical instance here.

Problem 2. Suppose that we add the two odd numbers. Prove why its addition is an even number always.
Solve: suppose that $(2 m+1)$ and $(2 n+1)$ are odd numbers that $m$ and $n$ are natural numbers. Then its addition is following as;

$(2 n+1)+(2 m+1)=2 m+2 n+2=2(m+n+1)$

Because, 2 is coefficient in this addition, we conclude that addition of two odd numbers is an even number always. In fact we proved that addition of two odd numbers is even number always for numbers which we have not added! As it is shown, we used of deductive reasoning when we informed of accuracy of pervious facts.

\section{Analogical reasoning}

Students find some concepts too abstract to solve. One of the strategies used to assist students with building conceptual knowledge is to use analogies. It is generally agreed that students' analogical reasoning increases significantly over the first few years of elementary school (Siegler \& Svetina, 2002). Students learn more about the world they are then able to use that increasing domain knowledge to reason about the relationships between items (Cheshire et al., 2000). Analogy allows students to apply commonalities between mathematical relations to help grasp new problems or concept through contributing to integral components of mathematical proficiency. Learning via analogy usually involves finding a set of systematic correspondences (a mapping) between a better-known source analog and a more novel target.

The source and the target can be within a single domain (e.g., solving inequalities is like solving equations) or across domains (e.g., balancing equations is like balancing a scale). Mathematical reasoning involves understanding abstract relations (such as equality, proportion, and integral) that can appear in different contents. Such abstract relations may be best taught by creating parallels between similar examples. Mathematics teachers have introduced analogy-based instruction in their classrooms commonly in the United States since many years ago. In this method, students are encouraged to solve problems even difficult problems (Richland et al., 2007).

A number of investigators have discussed the important role of analogical reasoning in science (Dreistadt, 1968) and education (Brown et al., 1978). It has been argued that analogies can play an important role in the creation of new theoretical hypotheses in science. In education, analogical reasoning may be important in the learning of such models and in the transfer of learned knowledge to new, unfamiliar situations. Previous investigations have also related analogical reasoning to problem solving (Polya, 1954), measures of intelligence (Sternberg, 1977), and the development of concepts (Clement, 1988). In analogical reasoning, we must consider to following items;

* Attempts to find cases that are alike to but different from the original or goal problem status;

* In regard to these attempts whether or not they yielded an answer to the problem finally;
Sci.Technol.Edu.

CIndian Society for Education and Environment (iSee)
"Instruction of mathematical concepts" http://www.indjst.org
S.A-Mofidi et al. Indian J.Sci.Technol. 
* Creating relation between trivial and non-trivial cases in analogical instance;

* Separating analogy generation from other problemsolving steps such as generating extreme cases, breaking a solution or thinking methods into independent parts, and analyzing the problem in terms of a theoretical principle.

Table 1. Analogies for basic algebra concepts

\begin{tabular}{|l|l|}
\hline \multicolumn{1}{|c|}{ Mathematical concepts } & \multicolumn{1}{|c|}{ Analogy } \\
\hline Solving equations & $\begin{array}{l}\text { Undressing a person vs. } \\
\text { Dressing a person }\end{array}$ \\
\hline Isolating a variable & $\begin{array}{l}\text { Peeling an onion one layer at } \\
\text { a time or shacking corn }\end{array}$ \\
\hline Collecting like terms & $\begin{array}{l}\text { Sorting out the mix fruits into } \\
\text { separate piles }\end{array}$ \\
\hline Distributive property & $\begin{array}{l}\text { Passing out papers from a } \\
\text { stack to each student in a } \\
\text { class }\end{array}$ \\
\hline $\begin{array}{l}\text { Substituting numbers for } \\
\text { the variables }\end{array}$ & $\begin{array}{l}\text { Putting a thing in the place of } \\
\text { another thing. }\end{array}$ \\
\hline
\end{tabular}

Sarina and Namukasa (2010) have introduced many analogies for better learning in mathematics and students used of analogical reasoning for self-learning. The above Table is a collection of some of analogies most frequently used to explain basic algebra concepts;

Analogies such as "equations are like a balanced scale" are structural; they highlight various similarities: two sides of a scale, state of balancing, actions that keep the scale balancing; respectively for two sides of equation-equivalence, equivalent actions. Thinking of division as fitting things into a container is a visual analogy. Explaining multiplication in terms of directed movements on a number line combines a math and nonmath analogy. Some analogies such as "to isolate terms is like what you do to turn a complicated sentence into a simpler one" are propositional (Aubusson et al., 2006) and literal; they involve a few surface similarities (Lee, 2007). Analogical reasoning creates when specific, structural correspondences between objects and relations in the source and target are used to adapt the solution process learned for the source into an analogous procedure for solving the target. Here we have tried that introduced mathematical examples which indicate the analogical reasoning via students.

Problem 3. The teacher asks student that measured the school building height thereby ruler only. This problem is difficult for student. The student thinks that exist a solution for this problem. At noon, when he is walking, he is noticed that shadow length of building is very short so that could measure via ruler rather others times. Immediately he measures the shadow length of building and then measures the self-shadow in standup case via ruler. Then he considered the self-shadow with selfstature and also building along its shadow as sides of two right triangles (see Fig.2).
Vol. 5 No. 6 (June 2012)

ISSN: 0974- 6846

Fig. 2. An example of analogical reasoning

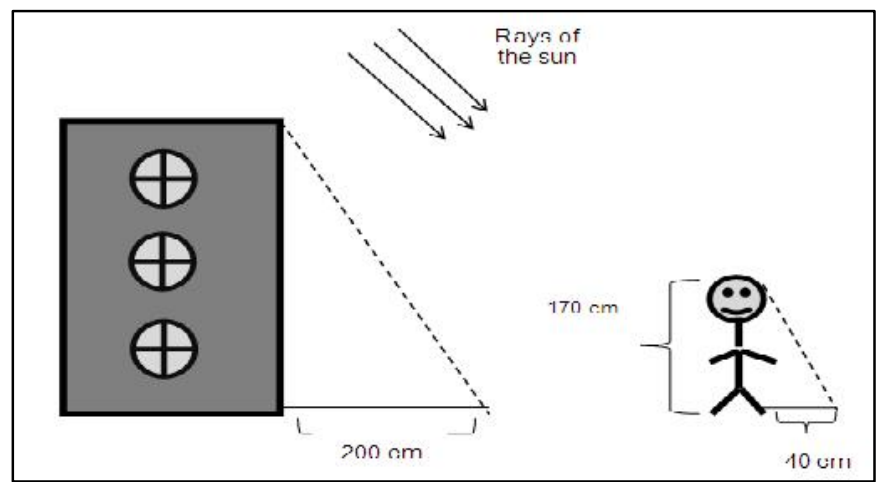

But was sufficient the information for identify of the school building height? Student ordered the self-information in Fig.3. Then he separated $B^{\prime} C$ with quantity of MP on the $B C$ side and he perpendicular $A^{\prime} B^{\prime}$ to $B C$ also. Because two $A^{\prime} B^{\prime}$ and $A B$ lines are perpendicular to $B C$ then are parallel therefore at respect of Thales theorem;

$\frac{\mathrm{AB}}{\mathrm{A}^{\prime} \mathrm{B}^{\prime}}=\frac{\mathrm{BC}}{\mathrm{B} \prime \mathrm{C}}=\frac{\mathrm{AC}}{\mathrm{A}^{\prime} \mathrm{C}}$

Fig.3. An example of analogical reasoning-mathematical description

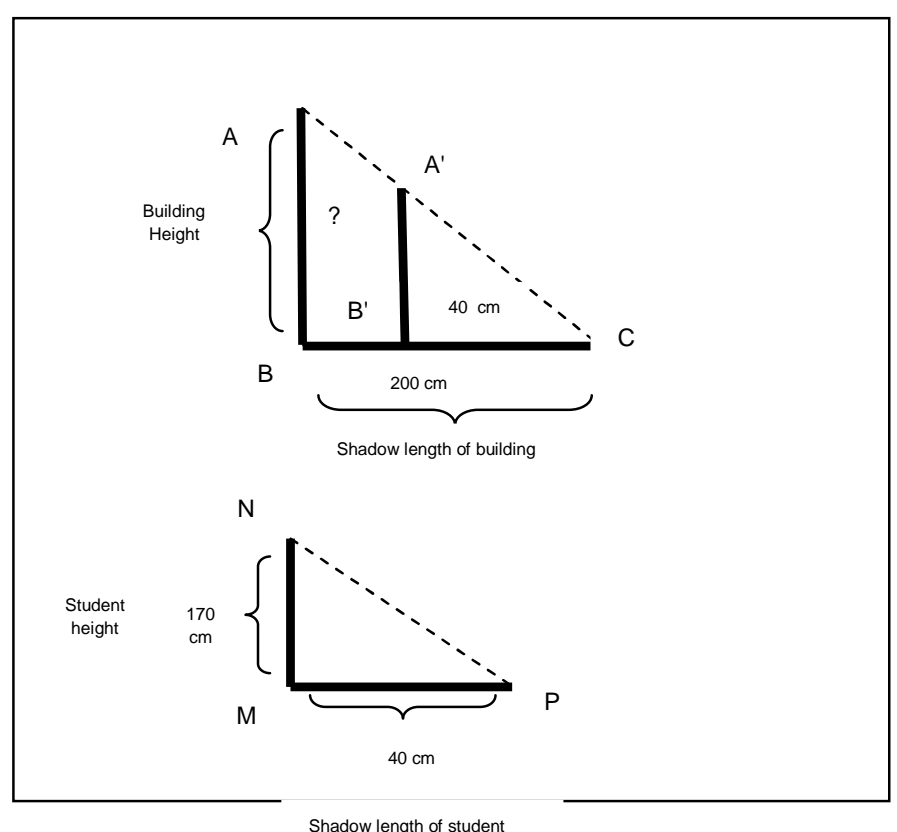

The student used of congruent triangles; $\triangle A^{\prime} B^{\prime} C^{\prime}$ and $\triangle$ NMP then gets to $\left(A^{\prime} B^{\prime}=N M\right)$ and replaces in (12):

$\frac{\mathrm{AB}}{\mathrm{NM}}=\frac{\mathrm{BC}}{\mathrm{MP}}$

$\frac{\mathrm{AB}}{170}=\frac{200}{40}$

or

$\mathrm{AB}=\frac{170 \times 200}{40}$

Then

Building height $=A B=850 \mathrm{~cm}$
Sci.Technol.Edu.

(C)Indian Society for Education and Environment (iSee)
"Instruction of mathematical concepts" http://www.indjst.org 
In Fig.3, $\angle C$ is common in two angles; $\triangle A B C$ and $\triangle A^{\prime} B^{\prime} C^{\prime}$ and $\angle B$ and $\angle B^{\prime}$ are equal and right. Then $\angle A$, $\angle A^{\prime}$ are equal too. Also two angles; $\triangle A B C$ and $\triangle N M P$ are congruent triangles therefore angles of two respected triangles are equal too. On the other hands $\left(M N=A^{\prime} B^{\prime}\right)$, $\left(M P=B^{\prime} C\right)$ and $\left(N P=A^{\prime} C\right)$, then the relation $(12)$ is:

$$
\frac{\mathrm{AB}}{\mathrm{MN}}=\frac{\mathrm{BC}}{\mathrm{MP}}=\frac{\mathrm{AC}}{\mathrm{NP}}
$$

That is sides of two respected triangles are proportionate. Then two triangles are analogous. Whole above steps is implemented and solve via the conversation between teacher and student. In fact student could attain to geometrical principle alone. First teacher created a challenge until student solved the problem. Teacher used of analogy for this problem and student applied self-reasoning for the analogy. Instances of analogies existed that we can use in mathematical context until students applied these analogies and reasoned. Here we stated the other mathematical example.

Problem 4: Find the root of $2 X+7=10$.

Solve: Many students of first grade of middle schools and high schools face to mistake in solving this problem. It is possible that they found the several values for $X$. In fact they have not noticed how solved this problem exactly. We can use of analogical instance until they reasoned of this analogical instance and generalized this reasoning for other same instances. The teacher used of this analogical instance:

Suppose a swimmer wants to pool. Certainly he has dressed until come to pool. He must disrobe then he will be able to dive. The line between rime of pool and floor is bound or mark. Backside of the bound or mark, he has dressed but when he dived to the pool (for side of the bound or mark), he must disrobe because if he was dived to pool with dress then his dress will sodden!

In this problem, the sign of (=) is as backside and for side of the pool's bound or mark. Ever numbers as swimmer that must transfer to the other side of $(=)$, must change its sign (must disrobe its dress). That is, if number was positive, its sign will be negative when transferred to the other side of $(=)$ vice versa. Therefore students used of this analogical reasoning for the other same problems

Fig. 4. The comparison between marks of control and experiment groups

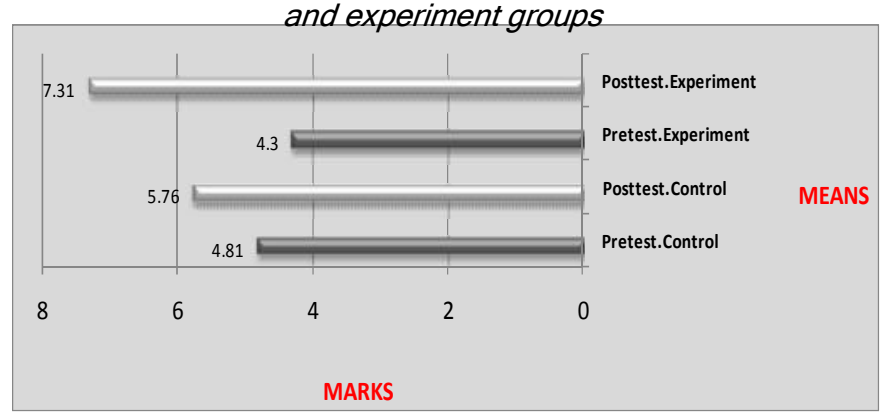

and could find corrective answer.

\section{Research hypothesis}

Instruction through analogical reasoning will improve the mathematical learning.

Method and collecting data

Researchers have used of quasi-experimental method for this research. In this method, researchers have selected two groups as control and experiment groups randomly. For studying, it is applied the usual instruction method for control group and researchers have used of the analogical reasoning method for mathematical instruction at first grade of high school. Analogical reasoning is applied for mathematics textbook in equations, geometry and elementary algebra. First it is implemented the pretests in two groups and it is cleared that control group's level is same experiment group. Then the analogical reasoning is applied in experiment group. Finally posttests are performed via researchers in both groups with same conditions.

\section{Participants}

In this study, one girly high school is selected in Karaj city (Alborz province) as the statistical society. In this high school, two first grades are selected as participants (38 students). In present research, 18 students and 20 students have participated in control and experiment groups respectively.

Table 2. Data of participants' marks in pretests and posttests of control and experiment groups

\begin{tabular}{|l|c|c|c|c|}
\hline & $\begin{array}{c}\text { Pretest. } \\
\text { Control }\end{array}$ & $\begin{array}{c}\text { Posttest. } \\
\text { Control }\end{array}$ & $\begin{array}{c}\text { Pretest. } \\
\text { Experiment }\end{array}$ & $\begin{array}{c}\text { Posttest. } \\
\text { Experiment }\end{array}$ \\
\hline $\mathrm{N}$ & 18 & 18 & 20 & 20 \\
\hline Mean & 4.81 & 5.76 & 4.3 & 7.31 \\
\hline Mode & 4.50 & 5 & 4 & 8 \\
\hline Variance & 2.77 & 2.04 & 1.99 & 2.26 \\
\hline
\end{tabular}

Research instrument

Two math exams are used for this research as pretests and posttests. These exams have 10 questions with 10 general marks. Its questions have two sections; numerical and word problems. In pretests, questions are designed so that evaluated the knowledge of students at pervious grades of school. For posttests, questions of exams evaluated the mathematical skills of students that were attained of analogical reasoning examples which designed via researchers. These exams have studied via specialist of mathematics and content reliability is emphasized and also validity of these exams is proved through Cronbakh's alpha; 0.89.

Table 3. The results of one-sample kolmogorov-smirnov test

\begin{tabular}{|l|c|c|c|c|}
\hline & $\begin{array}{c}\text { Pretest. } \\
\text { Control }\end{array}$ & $\begin{array}{c}\text { Posttest. } \\
\text { Control }\end{array}$ & $\begin{array}{c}\text { Pretest. } \\
\text { Experiment }\end{array}$ & $\begin{array}{c}\text { Posttest. } \\
\text { Experiment }\end{array}$ \\
\hline $\begin{array}{l}\text { Kolmogorov- } \\
\text { smirnov z }\end{array}$ & 0.55 & 0.39 & 0.56 & 0.78 \\
\hline $\begin{array}{l}\text { Sig. } \\
\text { (2-tailed) }\end{array}$ & 0.91 & 0.99 & 0.91 & 0.56 \\
\hline
\end{tabular}


Table 4. The results of independent samples test for pretests

\begin{tabular}{|l|c|c|c|c|c|c|c|c|c|}
\hline \multirow{2}{*}{ Pretests } & $\begin{array}{c}\text { Levene's test } \\
\text { for equality of } \\
\text { variances }\end{array}$ & \multicolumn{9}{|c|}{ T-test for equality of means } \\
\cline { 2 - 10 } & F & Sig. & T & Df & $\begin{array}{c}\text { Sig. } \\
\text { (2-tailed) }\end{array}$ & $\begin{array}{c}\text { Mean } \\
\text { difference }\end{array}$ & $\begin{array}{c}\text { Std. Error } \\
\text { difference }\end{array}$ & $\begin{array}{c}95 \% \text { confidence interval of the } \\
\text { difference }\end{array}$ \\
\hline $\begin{array}{l}\text { Equal variances } \\
\text { assumed }\end{array}$ & 0.69 & 0.4 & 1.04 & 36 & 0.3 & 0.51 & 0.49 & -0.49 & 1.53 \\
\hline $\begin{array}{l}\text { Equal variances not } \\
\text { assumed }\end{array}$ & & & 1.03 & 33 & 0.31 & 0.51 & 0.5 & -0.50 & 1.54 \\
\hline
\end{tabular}

Table 5. The results of independent samples test for posttests

\begin{tabular}{|c|c|c|c|c|c|c|c|c|c|}
\hline \multirow{3}{*}{ Posttests } & \multicolumn{2}{|c|}{$\begin{array}{l}\text { Levene's test } \\
\text { for equality of } \\
\text { variances }\end{array}$} & \multicolumn{7}{|c|}{ T-test for equality of means } \\
\hline & \multirow[t]{2}{*}{$F$} & \multirow[t]{2}{*}{ Sig. } & \multirow[t]{2}{*}{$\mathrm{T}$} & \multirow[t]{2}{*}{ Df } & \multirow{2}{*}{$\begin{array}{c}\text { Sig. } \\
\text { (2-tailed) }\end{array}$} & \multirow{2}{*}{$\begin{array}{c}\text { Mean } \\
\text { difference }\end{array}$} & \multirow{2}{*}{$\begin{array}{l}\text { Std. Error } \\
\text { difference }\end{array}$} & \multicolumn{2}{|c|}{$\begin{array}{l}\text { 95\% confidence interval of the } \\
\text { difference }\end{array}$} \\
\hline & & & & & & & & Lower & Upper \\
\hline $\begin{array}{l}\text { Equal variances } \\
\text { assumed }\end{array}$ & 0.2 & 0.6 & -3.2 & 36 & 0.003 & -1.54 & 0.47 & -2.51 & -0.58 \\
\hline $\begin{array}{l}\text { Equal variances not } \\
\text { assumed }\end{array}$ & & & -3.2 & 35 & 0.002 & -1.54 & 0.47 & -2.51 & -0.58 \\
\hline
\end{tabular}

Findings

For study of the research hypothesis, it is used of descriptive and deductive statistic. In descriptive statistic, mean, mode and variances are estimated. For deductive statistic, researchers have applied One-Sample Kolmogorov-Smirnov test, Levene's Test and Independent Samples Test in 95\% confidence interval. In Table 2, the highest mean and mode is related to posttest of experiment group (Mean= 7.31, Mode= 8) rather the control group. Also the means of the control and experiment groups are same in pretests. For using the proper tests, researchers have used of One-Sample Kolmogorov-Smirnov test. The results of this test have indicated that data is normal $(P>0.05)$ in Table 3 . As it clears in Table 4, variances of pretests' marks are same and equal $(F=0.69, P>0.05)$. Also the results of independent samples have indicated that there is not significant difference between marks' means of control and experiment's pretests $(T=1.04, P>0.05)$. Therefore it obvious that knowledge level of students was same in two groups. In Table 5, variances of posttests' marks are same and equal $(F=0.2, P>0.05)$. In addition the results of independent samples have shown that there is significant difference between marks' means of control and experiment's posttests $(T=-3.2, P<0.05)$. Then it clears that instruction through analogical reasoning have improved the mathematical learning.

Conclusion

Learning with understanding also makes subsequent learning easier. Mathematics makes more sense and is easier to remember and to apply when students connect new knowledge to existing knowledge in meaningful ways. Analogies reasoning skills help students connect new mathematical knowledge to their existing experiential knowledge and thus facilitate understanding and memorization of mathematical concepts. Analogies reasoning make math a friendlier subject and less detached from students' experiential base. Everyday logic and out-of-school experiences start playing an active role in students' mathematical reasoning. In this research, it has shown kinds of the reasoning in mathematical via examples in particular analogical reasoning. Researchers were applied this reasoning for mathematical learning. The results have indicated that this reasoning have effected; 1) this reasoning improved the creativity in students, 2) abstract mathematical concepts related to real life of students, 3) using analogical examples developed the reasoning ability and motivation in problem solving moment, 4) through primary mathematical analogical examples, students could introduce and provide the others analogical reasoning and examples, and 5) analogical reasoning made to deep learning and remembering the mathematical concepts for long-term.

Therefore researchers introduced these suggestions for next researches; I) try to introduce analogical examples and develop this reasoning for whole mathematical textbooks, II) select the analogical examples exactly and correctly because it is possible that students reasoned incorrectly and made to misconception for them. This study has limitation. Analogical reasoning is performed via traditional instruments.

\section{References}

1. Aubusson PJ, Harrison AG and Ritchie SM (2006) Metaphor and analogy: Serious thought in science education. In PJ Aubusson, AG Harrison and SM Ritchie (Eds.), Analogy in science, 1-10. Dordrecht: Springer.
Sci.Technol.Edu.

(CIndian Society for Education and Environment (iSee)
"Instruction of mathematical concepts" http://www.indjst.org
S.A-Mofidi et al. Indian J.Sci.Technol. 
2. Arslan C, Ilkörücü Göcmencelebi S, Seden Tapan M (2009) Learning and reasoning styles of pre service teachers : inductive or deductive reasoning on science and mathematics related to their learning style. Procedia Social \& Behavioral Sci. 1, 2460-2465.

3. Bransford JD, Brown AL, Cocking RR, Donovan MS and Pellegrino JW (2000) How people learn: Brain, mind, experience, and school. National acad. press. Washington, US.

4. Brown JS, Collins A and Harris G (1978) Artificial intelligence and learning strategies. In H.F. O'Neil (Ed.), Learning strategies. NY: Academic.

5. Clement J (1988) Observed methods for generating analogies in scientific problem solving. Cognitive sci. 12, 563-586.

6. Cheshire AJ, Ball L and Lewis L (2000) Selfexplanation, feedback and the development of analogical Reasoning Skills: Microgenetic evidence for a meta-cognitive processing account. Dept. Psychology, Lancaster University, Lancaster, LA1 4YF, UK.

7. Dreistadt $R$ (1968) An analysis of the use of analogies and metaphors in science. J. Psycho. 68, 97-I 16.

8. Duval R and Egret MA (1989) Organisation déductive du discours, annales de didactique et de sciences Cognitives 2, pp 25-40, Strasbourg: IREM de Strasbourg.

9. Gentner D (1989) The mechanisms of analogical learning. In: Vosniadou $S$ and Ortony A. (Eds.) Similarity and analogical reasoning. NY: Cambridge Univ. Press.

10. Harverty LA, Koedinger KR, Klahr D and Alibali MW (2000) Solving inductive reasoning problems in mathematics: No-so-trivial pursuit, Cognitive Sci. 24. 249-298.

11. Hawk TF and Shah AJ (2007) Using learning style instruments to enhance student learning. decision sciences. J. Innovative Edu. 5(1), 1-17.

12. Heller P, Heller K, Henderson C, Kuo VH and Yerushalmi E (2001) Instructors beliefs and values about learning problem solving. http://groups.physics.umn.edu/physed/Talks/Heller\%2 OPERC01.pdf.

13. Holland J, Holyoak K, Nisbett R, Thagard PR (1986) Induction, Cambridge, MA: MIT Press. Gick $M$ and Holyoak K (1983) Scheme induction and analogical transfer. Cognitive Psychol. 15(1), 1-38.

14. Lee K, Kim M, Na G, Han D and SandHun S (2007) Induction, analogy, and imagery in geometric reasoning. Proce. $31^{\text {st }}$ Confe. Intl.Group Psychol. Maths. Edu. $3^{\text {rd }}$ Eds. J-H. Woo, H-C. Lew, K-S. Park and D-Y. Seo, Seoul: Seoul National Univ. pp: 145157.

15. Michalski R (1986) Understanding the nature of learning: issues and research directions. In: Michalski R, Carbonell J, Mitchell T. (Eds.) Machine learning: An
Vol. 5 No. 6 (June 2012)

ISSN: 0974- 6846

artificial intelligence approach. 2. Los Altos, CA: Morgan-Kaufman.

16. Michalski R (1989) Two-tiered concept meaning, inferential matching, and conceptual cohesiveness. In: Vosniadou S, Ortony A. (Eds.) similarity and analogical reasoning, NY: Cambridge Univ. Press.

17. Moreno A, Myller N and Sutinen E (2007) Inductive reasoning and programming visualization, an experiment proposal. Electronic Notes in Theoretical Comput. Sci. 178. pp: 61-68.

18. Mason J, Burton L and Stacy k (1991) Thinking mathematically. England, Addison-Wesley, Wokingham.

19.Pellegrino JW and Glaser R (1982) Analyzing aptitudes for learning: Inductive reasoning. In: Advances in instructional psychology (Vol. 2), Glaser $\mathrm{R}$ (editor), Lawrence Erlbaum Associates, Hillsdale, NJ.

20.Polya G (1954) Mathematics and plausible reasoning, Vol (I): Induction and analogy in mathematics. Princeton, NJ: Princeton Univ. Press.

21. Park $J$ and Han S (2002) Using deductive reasoning to promote the change of students. Conceptions about force and motion. Int/. J.Sci. Edu. 24(6), 593-609.

22. Richland L Zur OJ and Holyoak K (2007) Cognitive supports for analogies in the mathematics classroom. Forum education. pp:40.

23. Richland L, Holyoak K and Stigler J (2004) Analogy use in eighth-grade mathematics classrooms. Cognition \& Instruction. 22 (1), pp: 37.

24.Sarina VK and Namukasa I (2010) Non-math analogies in teaching mathematics. Procedia Social \& Behavioral Sci. 2. 5738-5743.

25.Sternberg RJ (1977) Intelligence, information processing, and analogical reasoning: The componential analysis of human abilities. Hillsdale, $\mathrm{NJ}$ : Erlbaum.

26. Schoenfeld AH (1992) Learning to think mathematically: Problem solving, meta cognition.

27. Siegler RS and Svetina M (2002) A micro genetic/cross sectional study of matrix completion: Comparing short-term and long-term change. Child Dev. 73,793-809.

28. Watters JJ and English LS (1995) Children's application of simultaneous and successive processing in inductive and deductive reasoning problems: Implications for developing scientific reasoning. J. Res. Sci. Teaching. 32(7), 699-714.

29.Zaman A, Jumani A, Ali A and Hussain A (2011) Predictive validity of scores in mathematics for reasoning ability in mathematics for grade 9 students in Khyber Pakhtunkhwa based on curriculum of mathematics. Procedia Social \& Behavioral Sci. 12. 588-594.

30. Zhu X and Simon HA (1987) Learning mathematics from examples and by doing, Cognition \& Instruction. 4,137-166.
Sci.Technol.Edu.

(CIndian Society for Education and Environment (iSee)
"Instruction of mathematical concepts" http://www.indjst.org
S.A-Mofidi et al. Indian J.Sci.Technol. 